\title{
Correction to: Bioaerosol measurements over a fattening period in a pig barn focused on the presence of Staphylococcus spp.
}

\author{
D. Haas (D) S. Köck • Th. Fritz • H. Galler • J. Habib • M. Kropsch • \\ T. Miskovic $\cdot$ P. Pless $\cdot$ M. Stonitsch $\cdot$ E. Zentner $\cdot$ F. F. Reinthaler
}

Published online: 3 January 2021

(C) The Author(s) 2021

\section{Correction to: \\ Aerobiologia \\ https://doi.org/10.1007/s10453-020-09658-4}

In the original publication of the article, the below errors have occurred.

In the Introduction section, in the sentence "The VDI standard specifies.....in humans and animals (VDI 4255 Part 4 2017)." the word "mesophilic"should be "enterococci".

In the Materials and Methods section, under the subtitle " 2.3 Cultivation and identification of the microorganisms" in the sentence "For calculation of indicator.... media are listed in Table 1." the word "mesophilic"should be "enterococci".

In the results section, under the subtitle " 3.2 Quantitative analysis" in the sentence "Mesophilic is not shown in the table or in the figures." the word "Mesophilic"should be "Enterococci".

Finally, under the subtitle "3.2.1 Series I measurements" in the sentence "The concentrations of mesophilic bacteria .....then rose again in the M4-105 cfu/m3.", "M4-105 cfu/m3" should be "M4 to $10^{5} \mathrm{cfu} / \mathrm{m}^{3}$ “.

The original article has been corrected.

The original article can be found online at https:// doi.org/10.1007/s 10453-020-09658-4.

D. Haas $(\bowtie) \cdot$ S. Köck · Th. Fritz ·

H. Galler · J. Habib · T. Miskovic .

M. Stonitsch · F. F. Reinthaler

D\&R Institute of Hygiene, Microbiology and

Environmental Medicine, Medical University of Graz,

Graz, Austria

e-mail: doris.haas@medunigraz.at

M. Kropsch · E. Zentner

Research and Development, HBLFA Raumberg

Gumpenstein, Irdning-Donnersbachtal, Austria

P. Pless

Department of Veterinary Directorate and Administration

of the Styrian Government, Graz, Austria 